\title{
ГЕНЕРАЦІЯ ПРОЦЕСІВ САМООРГАНІЗАЦІї ТА САМОЗБОРКИ В БІОЛОГІЧНІЙ ТКАНИННІЙ ІНЖЕНЕРІЇ ТА РЕГЕНЕРАТИВНІЙ МЕДИЦИНІ
}

\author{
О. П. Мінцер, В. М. Заліський, Л. Ю. Бабінцева \\ Національна медична академія післядипломної освіти імені П. Л. Шупика
}

\begin{abstract}
В аналітичному дослідженні розглядаються самоорганізація та самозборка як процеси безкаркасної тканинної інженерії. Описано характеристики та переваги кожного процесу, а також надано ключові приклади тканин, створених із використанням цих процесів на основі безкаркасних тканєінженерних платорорм, з метою намітити рекомендації для майбутніх розробок тканинної інженерії в умовах клініки. Постулюється, що одним із найбільш перспективних напрямів досліджень слід визнати процес самозборки, який призводить до фрормування фрункціональної тканини клітинним способом, що не вимагає зовнішнього введення енергії. У той же час обґрунтування та ідентифікація оптимальної по заданому критерію системи фрормування складної тканини - вільної від скаффролда або заснованої на скафрфолді - представляє нетривіальне завдання поєднання різних систем і незалежних типів клітин.
\end{abstract}

Ключові слова: самоорганізація, самозборка, тканинна інженерія, тканєінженерна платформа, безкаркасні платсрорми, кісткова, серцево-судинна та печінкова тканини, рогівка.

\section{GENERATION OF SELF-ORGANIZATION AND SELF-ASSEMBLY PROCESSES IN BIOLOGICAL TISSUE ENGINEERING AND REGENERATIVE MEDICINE}

\author{
O. P. Mintser, V. M. Zaliskyi, L. Yu. Babintseva \\ Shupyk National Medical Academy of Postgraduate Education
}

\begin{abstract}
Background. An analytical study examines the processes of self-organization and self-assembly as processes of frameless tissue engineering. The characteristics and advantages of each process are described, and key examples of fabrics created using these processes on the basis of frameless tissue-engineering platforms are considered in order to outline recommendations for future tissue engineering developments in the clinic.

Purpose. The purpose of this review is to integration of achievements in the field of frameless tissue engineering, primarily associated with self-organization and the process of self-assembly.

Results. Materials and methods. It is postulated that one of the most promising areas of research is the self-assembly process, which leads to the formation of functional tissue in a cellular way that does not require external energy input. At the same time, the justification and identification of the system of complex tissue formation optimal by a given criterion free from a scaffold or based on a scaffold - is a non-trivial task of combining various systems and independent cell types.

Conclusion. One of the most promising areas of research is the self-assembly process, which leads to the formation of functional tissue in a cellular way that does not require external energy input. The justification and identification of a system of complex tissue formation optimal by a given criterion — free from a scaffold or based on a scaffold — is a non-trivial task of combining various systems and independent cell types.
\end{abstract}

Key words: self-organization, self-assembling, tissue engineering, tissue engineering platforms, bone, cardiovascular, liver and corneal tissues.

\section{ГЕНЕРАЦИЯ ПРОЦЕССОВ САМООРГАНИЗАЦИИ И САМОСБОРКИ В БИОЛОГИЧЕСКОЙ ТКАНЕВОЙ ИНЖЕНЕРИИ И РЕГЕНЕРАТИВНОЙ МЕДИЦИНЕ}

\author{
О. П. Минцер, В. Н. Залесский, Л. Ю. Бабинцева \\ Национальная медицинская академия последипломного образования имени П. Л. Шупика

\begin{abstract}
В аналитическом исследовании рассматриваются самоорганизация и самосборка как процессы бескаркасной тканевой
\end{abstract} \\ инженерии. Описаны характеристики и преимущества каждого процесса, а также представлены ключевые примеры тка- \\ ней, созданных с использованием этих процессов на основе бескаркасных тканеинженерных платорорм, с целью наметить \\ рекомендации для будущих разработок тканевой инженерии в условиях клиники. Постулируется, что одним из наиболее \\ перспективных направлений исследований следует признать процесс самосборки, приводящий к формированию фрункци- \\ ональной ткани клеточным способом, не требующим внешнего ввода энергии. В то же время обоснование и идентифика- \\ ция оптимальной по заданному критерию системы фрормирования сложной ткани - свободной от скафрфолда или осно- \\ ванной на скаффолде - представляет нетривиальную задачу сочетания различных систем и независимых типов клеток.
}

Ключевые слова: самоорганизация, самосборка, тканевая инженерия, тканеинженерная платорорма, бескаркасные платорормы, костная, сердечно-сосудистая, печеночная и роговичная ткани.

(с) О. П. Мінцер, В. М. Заліський, Л. Ю. Бабінцева 
Введение. Образование и рост нативных тканей - сложные процессы, которые часто требуют длительного (месяцы, годы) скоординированного внутриклеточного сигналинга $[27,28]$. Одной из проблем тканевой инженерии является то, что отдельные важные и естественно протекающие биологические процессы in vivo, приводящие к формированию ткани, могут отсутствовать в условиях in vitro. К их числу относится гипотеза о дифференциальной адгезии (DAH, differential adhesion hypothesis), которая обосновывает успешное формирование морфогенетической структуры тканей в процессе морфогенеза [12] и выступает в качестве независимого клеточного феномена.

Выдвинутая ещё в 1960-х годах данная гипотеза предполагает важность изменения поверхностного натяжения агрегатов клеток in vitro, а также то, что клеточные агрегаты с более низким поверхностным натяжением стремятся к прилипанию в участках с более высоким поверхностным натяжением [12].

Авторы заключили, что роль клеточной жидкости состоит в сортировке клеток для процесса самосборки клеточных агрегатов, а поверхностное натяжение клеточных агрегатов является прямой линейной функцией уровня экспрессии гена кадгерина. Таким образом, важным фактором для тканевой инженерии явилась необходимость развития биотехнологий - воспроизводства спонтанного тканевого роста. Оказалось, что в процессе самоорганизации и самосборки in vitro проявляются фундаментальные биологические процессы, которые спонтанно происходят in vivo и включают клеточные взаимодействия.

Процесс самоорганизации на уровне тканей обеспечивает соединение тканей в эмбриогенезе [43], благодаря контактированию клеток различных популяций и ремоделированию структур межклеточного матрикса. Необходимо отметить, что биологический процесс, подобный соединению (слиянию) тканей в эмбриогенезе (в единое целое) происходит при самоорганизации и самосборке в биоинженерии костно-мышечной нейросенсорной и сердечно-сосудистой тканей $[3,11,18]$.

Тканевая биоинженерия, разработанная путём объединения знаний из молекулярной биологии, материаловедения, биомеханики и медицины, необходима для производства тканевых биоконструкций с целью ремонта или замены тканей скомпроментированных травмой, патологией или возрастом. Центральное место в этой программе занимает использование свободных от биокаркасов (скаффолдов) подходов, позволяющих изготавливать ткани для клинических и экспериментальных целей.

Цель работы: интеграция достижений в области бескаркасной тканевой инженерии, связанной в первую очередь с самоорганизацией и процессом самосборки [2].

Результаты и их обсуждение. Рассмотрим вначале особенности исследований в области традиционной тканевой биоинженерии и механизмы генерации процессов самоорганизации и самосборки. Компонентами триады биоинженерии являются клетки, биоматериалы (биологические каркасы, биоконструкции, скаффолды) и биоактивные сигнальные белки. Клетки, необходимые для формирования тканей, должны находиться в пределах скаффолдов.

Стратегии тканевой инженерии всё чаще включают использование соматических стволовых клеток (СК) и их предшественников, эмбриональные и индуцированные плюрипотентные СК из-за их способности к самообновлению $[1,28]$. Сигналы или стимулы (например, механические, электрические, биохимические), а также их комбинации, крайне необходимы для образования новых тканей [12].

Развитие биологических каркасов является наиболее исследованной областью парадигмы тканевой биоинженерии. Экзогенные биоконструкции позволяют клеткам позиционироваться в процессе пролиферации, дифференцироваться, а также совместно с регуляторными белками внеклеточного матрикса участвовать в формировании 3D структуры биоконструкции. Так как клетки по-разному реагируют на скаффолды различной жесткости, манипулирование их жёсткостью может быть полезным подходом для управления клеточными реакциями [39]. Изменяя пористость биоконструкции, можно увеличить её насыщенность клетками [7]. В тоже время для некоторых клеток жёсткость биоконструкции очень важна в плане надёжного прикрепления к субстрату [8].

Скаффолды длительное время позволяют контролировать дозированный выход факторов роста и других белков в окружающую микросреду, после имплантации биоконструкции [60]. Всё это делает возможным эффективно планировать стратегию тканевой инженерии на основе применения скаффолдов.

Однако ремоделирование образующейся новой ткани способствует появлению снижения 
функциональных свойств, цитотоксичности и иммуногенности подверженных деградации биоконструкций в процессе её использования [31]. К тому же клетки, находящиеся в контакте со скаффолдом, изменяют свой фенотип [29] в результате их дифференцировки.

Несмотря на эти недостатки сильная мотивация исследователей относительно использования биоконструкций в клинической и экспериментальной медицине делает перспективной эту ещё сравнительно молодую область.

За последние три десятилетия появились методы так называемой бескаркасной (scaffoldles) биоинженерии, позволяющие использовать разные платформы. Среди них: пеллетная культура (pellet culture) и ротационная культура (rotation culture). Созданы биотехнологии образования сфероидов или агрегатов: висячей капли (hanging drop), а также - биотехнологии самосборки (self-assembly) и масштабной самоорганизации, включающие разработку платформы клеточного листа (cell sheet) для генерирования биоконструкции клинически значимых размеров [2, 28, 36].

Одним из перспективных методов тканевой инженерии, особенно в области разработки хрящевой ткани, является индукция самосборки $[2,28]$.

Значение имеет применение корректных дефиниций. Важно прояснить различия между самоорганизацией и процессом самосборки. В классических фундаментальных исследованиях они основаны на положениях термодинамики. В соответствии с последними самоорганизация описывает процесс, в котором появляется порядок, когда внешняя энергия или силы вводятся в систему [63]. В отличие от самоорганизации, для процесса самосборки никакие внешние силы для обеспечения порядка не требуются. Таким образом, самоорганизация и процесс самосборки происходят в открытых и закрытых системах соответственно [62].

Самоорганизация в тканевой инженерии может быть определена как подмножество методов в рамках бесшаблонной тканевой инженерии, которые производят ткани, демонстрирующие организацию с использованием внешних сил.

Самосборка определяет развитие событий без участия влияния энергии извне. Для генерации функциональной хрящевой ткани с характеристиками, напоминающими нативную ткань хряща, самосборка означает процесс без дополнительной энергии. При этом неадгезивные (агарозу-содержащие) субстраты клеточной культуры поддерживают высокую плотность посева хондроцитов в формировании хондрогенного фенотипа. Оказалось, что клеточная адгезия регулируется в хроноцитах [48] на начальном этапе процесса самосборки, благодаря процессам дифференциальной адгезии поверхностно связанных молекул и дифференциального межфазного натяжения [49].

Гипотеза дифференциальной адгезии предполагает, что исходно в новой ткани минимизировано количество свободной энергии (в условиях клетка-клеточного взаимодействия). Тип и количество белков адгезии, присутствующих на поверхности клетки, обеспечивают состояние межклеточных контактов. В то же время, клеточная масса ведёт себя аналогично внутриклеточной жидкости и минимизирует своё поверхностное натяжение, известное как поверхностное натяжение ткани. Это натяжение определяет сортировку клеток в смешанной популяции, так как клетки с более высоким поверхностным натяжением будут стремиться к центру, максимизируя объемы межклеточной адгезии. Следовательно, поверхностное натяжение ткани снижается. Аналогично в процессе самосборки (in vitro) неадгезивный субстрат (внутриклеточная жидкость) стимулирует однородную клеточную популяцию минимизировать свободную энергию за счет присоединения новых клеток, чему способствует повышенный уровень N-кадгерина и других поверхностно связанных молекул адгезии [13, 48].

Другим механизмом, способствующим процессу самосборки, является дифференциальное межфазное натяжение. Поверхностное клеточное натяжение, вызванное сократительной способностью белка актина цитоскелета, также вовлечено в сортировку клеток [56]. Как и в случае дифференциальной адгезии поверхностно связанных молекул, минимизация свободной энергии стимулирует поведение клеток согласно гипотезе дифференциального межфазного натяжения. При этом сортировка клеток происходит под контролем влияния клеточного цитоскелета и клеточной мембраны. В частности, клетки, порождающие подобное натяжение, имеют тенденцию к усиленной агрегации, по сравнению с теми, для которых не характерна такая способность. К тому же оказалось, что процессы дифференциальной адгезии поверхностно связанных молекул и дифференциального межфазного натяжения взаимосвязаны [56]. Хотя более глубокое понимание относительно вклада каждого процесса в механизме самосборки ещё предстоит исследовать. 
Необходимо отметить, что углублённые знания биологии развития могут помочь в будущем специалистам в области медицинской инженерии с помощью процесса самосборки оптимально управлять сортировкой клеток при использовании бескаркасной тканевой инженерии, а также экспрессией генов и эффективным соединением различных тканей.

Pellet культура - основной метод бескаркасной тканевой инженерии, требующий привлечения энергии из вне (благодаря центрифугированию небольших агрегатов клеток внутри конической центрифужной пробирки). При добавлении в культуру клеток ряда специфических регуляторных молекул белков удалось осуществить контроль процессов дифференцировки, экспрессии генов и образования структур внеклеточного матрикса в хрящевой, костной и печёночной тканях $[10,36]$.

Несмотря на это, Pellet культура не отвечает ряду клинических требований в медицинской инженерии, таких как: она способствует формированию робастности биомеханических свойств новой ткани, её оптимальной геометрии и клинически значимых размеров биоконструкций.

Агрегатная и сфероидная культура так, как и Pellet культура позволяет производить, как было отмечено ранее, клеточные агрегаты малого диаметра и включает биотехнологии висячей капли, v-образных пластин и ротационных культур, а также способствует поддерживанию клеток в 3D-микроокружении и может применяться для повышения тканеспецифической экспрессии кандидатных генов и целевых белков. С помощью биотехнологий подвешивания/ротации капель и v-образующих пластин удалось создать эффективные композитные материалы; а благодаря ротационной культуре стало возможно (в присутствии тканеспецифических факторов роста) осуществлять агрегацию и дифференцировку под контролем клетко-клеточного и клетко-матричного взаимодействий.

Перечисленные биотехнологии часто применяются при проектировании клинически значимых размеров тканевой биоконструкции [11]. Например, агрегатная культура поддерживает как дифференцировочный, так и редифференцировочный процессы и может применяться в других областях тканевой инженерии [57].

Биопринтинг (bioprinting) - метод использования целой серии композитов малого диаметра в составе так называемых «биологических чернил» (bioink), подающихся через малое сопло во время 3D печати. Последующее сплавление (fusion) множественных сфероидов-композитов мезенхимальных стволовых клеток в крупные биоконструкции позволило генерировать непрерывные хрящевые биокомплексы [42]. Таким образом, несмотря на то, что пеллетные или агрегатные культуры клеток могут пока ещё не позволить создавать биоконструкции клинически значимых размеров, эти методы крайне важны для формирования направленного фенотипа многих типов клеток и могут быть интегрированы в рамках более крупных проектов тканевой биоинженерии.

Биотехнология клеточного листа (cell sheet) - метод бескаркасной тканевой биоинженерии, который включает внешние манипуляции и тепловую энергию в целях формирования функциональных 3D тканей в условиях in vitro [19]. При этом клетки культивирутся в монослое на функционизированных подложках или на термореактивном полимере. Для быстрого использования клетки извлекаются путём энзиматического расщепления в пределах подложки. Кроме того, клетки (фибробласты человека) можно наносить на трубчатую опору-подложку, а после их созревания и удаления трубчатой опоры в просвет высеиваются эндотелиоциты, оптимизирующие производство тканеинженерных кровеносных сосудов in vitro [23]. В качестве альтернативы были разработаны термореактивные биополимеры, в которых при изменении температуры полимера изменяются конформационные свойства и индуцируется плотный контакт клеточных листов [4]. Слияние нескольких слоёв клеточных листов может использоваться для создания тканей большой толщины для воссоздания общей архитектуры ткани-мишени [18] клинически значимых размеров.

К преимуществам бескаркасной тканевой инженерии относятся:

1) создание условий для нативной интеграции тканей, интенсивного осаждения матриц и ограничения выделения вредных побочных продуктов;

2) ограничение развития гиперинтеграционных процессов;

3) биоконструирование тканей без скаффолдов позволяет избежать проблем цитотоксичности из-за выщелачивания биочастиц полимеризующими химикатами или пластификаторами при создании биоконструкций [52];

4) снижения вероятности развития иммунного ответа на чужеродные материалы [30]. 
K недостаткам бескаркасной тканевой инженерии относят несоответствие биотрансплантата функциональным свойствам нативных тканей. Например, если в локальный дефект бедренной кости поместить искусственный хрящ с более низкими механическими свойствами, то возникающий перепад поверхностного натяжения может сформироваться в пределах искусственного хряща, а также на границе с нативной тканью. Несовпадение функциональных свойств (особенно в случае несущих тканей) может привести к разрушению имплантата, если он не будет надлежащим образом разгружен после операции. По-видимому, в будущем, для повышения жизнедеятельности этих подходов, врачам понадобится разработка реабилитационных схем, специфических для бескаркасных биоконструкций [12, 37].

Бескаркасная тканевая инженерия в эксперименте и клинике. Применение метода бескаркасной инженерии на основе платформы листов остеогенных клеток (osteogenic cell sheet) способствовало успешному проведению таргетирования в процессе тканевой инженерии костной ткани и продемонстрировало важную роль листов мезенхимальных СК (свёрнутых в цилиндрические биоконструкции) в формировании минерализации и повышения прочности кости на сжатие [20]. Клеточная листовая структура размещается в костных дефектах критического размера для облегчения формирования новой ткани [7]. Имплантация in vivo способствует экспрессии генетических маркеров (например, коллагена I типа, остеокальцина и osterix) в клеточных листовых сокультурах остеогенных стромальных и эндотелиальных клеток, по сравнению с монокультурами остогенных клеток [39]. Однако в большинстве исследований не проводилась оценка механических свойств сформированных новых тканей, что обуславливает необходимость осуществления последующего анализа механических особенностей тканеинженерной кости in vitro. Также осуществление широкого спектра исследований скаффолд-независимых процессов (от дифференцировки до формирования крупных биоконструкций) улучшило бы наше понимание потенциала применения свободных от биокаркасов методов тканевой инженерии костной ткани.

Тканевая инженерия хряща остается не менее важным разделом предклинических исследований самосборки и самоорганизации [8]. Оказалось, что применение хондроцитов (в тканеинженерных платформах, свободных от биокаркасов), обработанных ферментом межклеточного матрикса (LOXL2, lysil-oxidase-like protein2), позволило достигнуть высоких значений жёсткости (на сжатие и растяжение) хрящевой ткани [24]. На основе комбинации применения биоактивных стимулов (биохимических: TGF- $\beta 1$, chondroitinase-ABC; а также механических — гидростатическое давление) удалось сформировать фенотип костнохондральных клеток в ткани суставного хряща [41]. Самосборка суставного хряща, полученного из первичных хондроцитов, культивируемых в хондрогенно-индуцирующей среде, обеспечивала выраженные функциональные свойства, характерные для нативных хрящевых тканей суставов [7]. Это позволяет надеяться на создание в будущем механически прочных и функционально эффективных (жизнеспособных) тканей хряща на основе бескаркасной биоинженерии [54].

Известно, что разрыв связок и сухожилий часто восстанавливается с помощью аутологичных и трупных трансплантатов, поставки которых ограничены. Тканевая инженерия связок и сухожилий, таким образом, стремиться заполнить эту потребность для замены повреждённых механически прочными тканями.

Методы клеточного листа в тканевой инженерии связок и сухожилий обладают способностью активировать контрактильные свойства засеянных клеток на покрытых ламинином подложках. Последующее отделение и самоорганизация клеток в стержнеобразные тканевые структуры (скрепление шелковыми швами) на фоне добавления факторов роста соединительной ткани и аскорбиновой кислоты, повышает тканевую жёсткость на растяжение, а также активирует коллаген I типа и tenomodulin [21, 47, 50].

В современных исследованиях биотехнологии самоорганизации стволовоклеточных листовых платформ тканеинженерных биоконструкций сухожилий позволяют достигать создания механически робастных тканей в условиях клиники [32, 44, 58, 59].

Индукция сфероидов в тканевой биоинженерии связок и сухожилий ограничивается возможностью проектирования дифференцировачных и фенотипических событий в обслуживании клеток при посевах на скаффолды. В тоже время индукция клеточных сфероидов, созданных из клеток передней крестообразной связки, была взаимоувязана с активацией коллагена и тенасцина С [45]. Отмечено также, 
что агрегаты теноцитов (tenocytes) на платформе «висячей капли» индуцируют также усиление экспрессии сухожилия-ассоциированных генов (коллаген III типа и scleraxis) по сравнению с монослойными культурами [6].

При инфаркте миокарда часто значительные участки сердца повреждаются и не могут адекватно проводить электрические импульсы. Тканевая биоинженерия в кардиологии призвана обеспечить замену повреждённых тканей для восстановления функций (электрической проводимости и механической контрактильности) сердечной мышцы, наряду с васкуляризацией искусственных тканей сердца перед имплантацией. Платформа «клеточного листа» применяется для формирования трехмерной структуры биоконструкции ткани сердца, способной к электрогенезу. При этом синхронные и спонтанные биения возникают в результате наслоений культивированных листов с кардиомиоцитами, полученными от эмбриона [22]. Электрическая связь между ними осуществляется благодаря белкам межклеточных контактов (connexin-43) [9], а метаболические потребности кардиомиоцитов искусственной ткани обеспечивались васкуляризацией слоёв трансплантата in vivo [33].

Пошагово осуществляемая трансплантация десяти трёхслойных кардиомиоцитных листов, культивируемых совместно с эндотелиальными клетками, способствовала васкуляризации in vivo, что приводило к одновременному сокращению 30ти слойной искусственной ткани сердца $[18,46]$. Таким образом, оказалось, что как электрическая проводимость, так и синхронные сокращения тканеинженерной биоконструкции сердца могут достигаться благодаря применению тканевой инженерной платформы «cell sheet». С другой стороны исследования показали возможность индукции васкуляризации in vivo с помощью тканеинженерной биотехнологии «клеточного листа». Но для перевода синтетических регенеративных материалов и их использования в кардиологической клинике необходимы дополнительные исследования для анализа особенностей васкуляризации трансплантата in vitro, а также интеграция всех типов тканей сердца in vivo [25, 26, 38, 51, 55] и уточнение кардиомиогенного потенциала стволовых клеток плаценты [5], с одновременным совершенствованием биоинженерной структуры биореакторов, в которых рекапитуляция (recapitulation, повторение признаков ткани) функциональных, биохимических и физиологических характеристик сердечной ткани может быть использована для воссоздания её естественного микроокружения [40, 54].

Сравнительно новая биотехнология самоорганизации и самосборки биомиметической ткани позволила сформировать трубчатый микрососуд (in vitro) на основе последовательного наложения «клеточных листов» васкулярных и эндотелиальных клеток, который способен выдерживать давление «на разрыв» 2000 мм. рт. ст. ( $265 \mathrm{kPa})$ [23]. Интеграция этого метода в формате фибробласты/эндотелиоциты позволила выдержать давление разрыва более 3500 мм. рт. ст. ( $465 \mathrm{kPa}$ ) in vivo на протяжении 8 месяцев [53].

Современная методика создания сосудистых трансплантатов из мезенхимальных стволовых клеток костномозгового происхождения (и обработанных аскорбиновой кислотой) позволила достигнуть формирования сосудистых трансплантатов малого диаметра, но с достаточной плотностью стенок [14], а её оптимизация платформой «клеточного листа» на основе коллаген/поли ( $\varepsilon$-капролактона) способствовала повышению прочности на растяжение и оптимизации клеточной жизнеспособности с возникновением устойчивого сосудистого фенотипа [35].

Тканевая инженерия печени предназначена как для сохранения фенотипа печёночных клеток в культуре, так и для дифференцировки клеток-предшественников в зрелые гепатоциты. Регулированием размеров индуцируемых сфероидов (или агрегатов) гепатоцитов при проведении бескаркасной биоинженерии печени удалось сохранить уровни экспрессии специфического печеночного альбумина в 3D-структуре биоконструкции [2]. Ко-культура гепацитов с другими типами клеток («звездчатые клетки») способствовала индукции повышенной экспрессии альбумина и цитохрома р450 по сравнению только с гепатоцитами. Кроме того, ко-культура с панкреатическими островковыми клетками сохраняла гепатоцитарные и панкреатические фенотипы в гибридном сфероиде. Опорные клетки в структуре сфероида способствовали сохранению стабильности фенотипа гепатоцитов и их позитивному потенциалу в долгосрочном восстановлении функции органа при имплантации in vivo.

Проектирование функциональных двух- и трёхмерных печёночных биоконструкций in vivo с применением биотехнологии «клеточного листа» продемонстрировало робастную экспрессию альбумина благодаря использованию 
иммуногистохимического контроля [2]. В дополнение к робастной продукции альбумина и анти-трипсина альфа1 (A1AT, alpha1 anti-trypsin), гепациты в формате «cell sheet» со-культурированные с фибробластами повышали васкуляризацию печёночных трансплантатов человека, расположенных подкожно у мышей, что обеспечивало выживание пересаженной искусственной печёночной ткани. Авторы полагают, что свободные от скаффолда «cell sheet» - гепациты могут самостоятельно или в со-культуре поддерживать основные функции печени и обеспечить инициацию васкуляризации имплантированных тканей in vivo.

Другие приложения технологии. Роговица является прозрачной структурой глаза, обеспечивающей механическую защиту глаза, и служит оптическим интерфейсом. Для преодоления дефицита донорской роговицы изучается альтернативное применение тканеинженерных биоконструкций роговицы в клинике [17]. Создана клеточная листовая платформа на основе аутологических клеток эпителия слизистой оболочки полости рта, которая способствовала восстановлению прозрачности роговицы, её естественной барьерной функции и улучшения остроты зрения у человека [16]. Ранее данная методика была продемонстрирована на модели роговицы кролика [38]. Создание трансплантируемых слоёв эндотелиальных клеток роговицы человека (HCEC, transplantable human corneal endothelial all layers) на основе полимерного термочувствительного носителя позволило регулировать толщину слоя, жёсткость и функционализацию тканеинженерной платформы эндотелия роговицы, а также помогло существенно улучшить терапевтические возможности контроля заболеваний роговицы, приводящих к тяжёлому ухудшения зрения. Проектирование только совместных функциональных параметров эпителиальных клеток и эндотелия стромы роговицы может позволить создание трансплантатов роговицы оптимальной толщины [17, 34].

Коррекция эректильной дисфункции. Авторы исследования [61] акцентировали внимание на том, что поскольку треть пациентов с эректильной дисфункцией (Эд) не реагируют на ингибиторы фосфодиэстеразы-5, существует большой спрос на новые терапевтические варианты. Стволовые клетки, полученные из жировой ткани (Adipose tissue-derived stem cells — ADSCs), представляют собой идеальный источник для нового лечения ЭД. Полученные результаты показали способность
ADSCs дифференцироваться в гладкомышечные и эндотелиальные клетки, а значит, и формировать кавернозную ткань. Кавернозная ткань, изготовленная из ADSCs, определяет новую технологию улучшения выживаемости стволовых клеток in vivo и лечения ЭД.

Заключение. За последние несколько десятилетий биотехнологии тканевой инженерии сделали существенные шаги к созданию функциональных тканей in vitro, способных заменить повреждённые болезнью, травмой или возрастом. Бескаркасная тканевая биоинженерия явилась альтернативным подходом, включающим только клеточный и сигнальный контекст, стремясь обеспечить преимущества строительных блоков на безскаффолдовой основе.

В бескаркасных биоконструкциях процессы самоорганизации и самосборки различаются на основе использования или не использования внешней энергии. В зависимости от той или иной тканимишени предпочтительным может оказаться либо скаффолд, либо свободная от скаффолда основа. Последнее достижение (на фоне существующих ограничений) биомиметической тканевой инженерии (in vitro) позволили направлено восстанавливать функцию повреждённых тканей-мишеней и облегчать применение метода в условиях клиники.

Поиск клеток, которые получают из естественных источников, является наиболее важным фактором, ограничивающим развитие тканевой инженерии. Используя протоколы индукции сфероидов или агрегатов (методы «висячей капли», «V-образных платин» или «клеточных листов») можно эффективно продвигать необходимый фенотип клеток в 3D-среде, а также достигнуть желаемого уровня дифференцировки in vitro. После этого клетки могут быть использованы на основе скаффолда или бескаркасной платформы (строительных белков-биокомпозитов) в целях создания биоконструкций клинически значимых размеров.

Более глубокое понимание процессов в области биологии развития, посредством которых развиваются различные ткани и органы, может помочь в выборе методов, свободных от биокаркасов, или основанных на скаффорд-ассоциированных тканеинженерных платформах.

Ключевым направлением исследований, позволяющих обеспечить долговременную функционализацию тканей с помощью биотехнологии клеточной культуры и не требующей внешних затрат энергии, являются 
процессы самоорганизации исамосборки. В некоторых типах тканей (например, хрящевой) процесс самосборки имитирует естественные механизмы морфогенеза в рамках биологии развития. Понимание процессов развития может быть адаптировано к методам самосборки и способствовать появлению новых подходов, обеспечивающих повышение долгосрочной функциональности трансплантированных тканеинженерных биоконструкций. В конечном итоге, достигается такой уровень сложности спроектированных тканей, который позволяет новой ткани не только восстанавливать нативную функцию в пределах тканевого микроокружения, но и активировать процесс регенерации.

\section{Литература.}

1. Тимченко А. С. Мезенхимальные и опухолевые стволовые клетки: механизмы иммуновоспалительной модуляции стволовых клеток при персонализованной медицине: монография / Тимченко А. С., Залесский В. Н. - К.: Мединформ. - 2018. - 594 с.

2. Athanasion K. A. Seff-organization and self-assembly process in tissue engineering / Athanasion K. A., Eswaramoorthy R., Hadidi P. et al. // Annu. Rev. Biomed. Eng. - 2013. - 15. - P. 115-136.

3. Baltich J. Development of scaffoldless three-dimensional engineered nerve using a nerve fibroblast co-culture / Baltich J., Hatch-Vallier L., Adams A. M. et al. // In Vitro Cell Dev. Biol. Anum. - 2010. - 46. - P. 438-444.

4. Brown W. E. Overcoming Challenges in engineering large, scaffold-free neocartilage with functional properties / Brown W. E., Huang B. J., Keown T., Hu J. C., Athanasion K. A. // Tissue Eng. Part A. - 2018. - 24 (21-22). - P. 1652-1662.

5. Bollini S. Cardiac restoration stemming from the placenta tree: Insights from fetal and perinatal cell biology / Bollini S., Silini A. R., Banerjee A. et al. // Front Physiol. - 2018. - 9. - P. 385.

6. Calve S. Implantation increases tensile strength and collagen content of self-assembled tendon constructs / Calve S., Lytle I. F., Grosh K. et al. // J. Appl. Physiol. - 2010. - 108. - P. 875-881.

7. Dean D. M. Cytoskeletal-mediated tension modulates the directed self-assembly of microtissues / Dean D. M., Morgan J. R. // Tissue Eng. Part A. - 2008. - 14. P. 1989-1997.

8. Discher D. E. Tissue cells feel and respond to the stiffness of their substrate / Discher D. E., Janmey P., Wang Y. L. // Science. - 2005. - 310. - P. 1139-1143.

9. Donnelly K. A novel bioreactor for stimulating skeletal muscle in vitro / Donnelly K., Khodabukus A., Philp A. et al. // Tissue Eng. Part. C. Methods. - 2010. - 16. P. 711-718.

10. Elder S. H. Chondrocyte response to cyclic hydrostatic pressare in alginate versus pellet culture / Elder S. H.,
Выводы. 1. Одним из наиболее перспективных направлений исследований следует признать процесс самосборки, приводящий к формированию функциональной ткани клеточным способом, не требующим внешнего ввода энергии.

2. Обоснование и идентификация оптимальной по заданному критерию системы формирования сложной ткани - свободной от скаффолда или основанной на скаффолде - представляет нетривиальную задачу сочетания различных систем и независимых типов клеток.

Sanders S. W., Mc Culley W. R. et al. // J. Orthop. Res. - 2006. - 24. - P. 740-747.

11. Eiraku M. Self-organizing optic-cup morphogenesis in three-dimensional culture / Eiraku M., Takata N., Ishibashi H. et al. // Nature. - 2011. - 472. - P. 51-56.

12. Foty R. A., Steinberg M.S. The differential adhesion hypothesis: a direct evaluation / Foty R. A., Steinberg M. S. // Dev. Biol. - 2005. - 278. - P. 255-263.

13. Furukawa K. S. Rapid and large-scale formation of chondrocyte aggregates by rotational culture / Furukawa K. S., Suenaga H., Toita K. et al. // Cell Transplant. 2003. - 12. - P. 475-479.

14. Ganvin R. A novel single-step self-assembly approach for the fabrication of tissue-engineering vascular constructs / Ganvin R., Ahsan T., Larouche D. et al. // Tissue Eng. Part A. - 2010. - 16. - P. 1737-1747.

15. Ghezzi C. E. Corneal tissue engineering: recent advance and future perspective / Ghezzi C. E., Rnjak-Kovacina J., Kaplan D. L. // Tissue Eng. Part. B. Pev. - 2015. - 21 (3). - P. 278-287.

16. Griffith M. Artificial corneas: a regenerative medicine approach / Griffith M., Jackson W. B., Lagali N. et al. // Eye (Lond). - 2009. - 23. - P. 1985-1989.

17. Griffith M. Recent advances in the design of artificial corneas / Griffith M., Harkin D. G. // Curr. Opin. Ophthalmol. - 2014. - 25 (3). - P. 240-247.

18. Halley J. D. Consistent concepts of self-organization and sell-assembly / Halley J. D., Winkler D. A. // Complexity. - 2008. - 14. - P. 10-17.

19. Haraguchi Y. Fabrications of functional threedimensional tissues by stocking cell sheets in vitro / Haraguchi Y., Shimizu T., Sasagawa T. et al. // Nat. Protoc. - 2012. - 7. - P. 850-858.

20. Harris A. K. Is cell sorting caused by differences in the work of intercellular adhesion? A critical of the Steinberg hypothesis / Harris A. K. // J. Theor. Biol. - 1976. - 61. - P. 267-285.

21. Huang Y. C. Rapid formation of functional muscle in vitro using fibril gels / Huang Y. C., Dennis R. G., Larkin L. et al. // J. Appl. Physiol. 2005. - 98. - P. 706-713. 
22. Huang Y. C. Cultured slow versus skeletal muscle cells differ in physiology and responsiveness to stimulation / Huang Y. C., Dennis R. G., Baar K. // Am. J. Physiol. Cell Physiol. - 2006. - 291. - P. 11-17.

23. Jakab K. Tissue engineering by self-assembly and bioprinting of living cells / Jakab K., Narotte C., Marga F. et al. // Biofabrication. - 2010. - 2. - P. 022001.

24. Kinoshita N. Apical accumulation of Rho in the neural plate in important for neural plate cell shape change and neural tube formulation / Kinoshita N., Sasai N., Misaki K. et al. // Mol. Biol. Cell. - 2008. - 19. - P. 2289-2299.

25. Komae H. Sell sheet-based vasenlarized myocardial tissue fabrication / Komae H., Ono M., Shimiru T. // Eur. Surg. Res. - 2008. - 59 (3-4). - P. 276-285.

26. Lai A. L. Biomimetic approaches for cell implantation to the restoration of infarcted myocardium / Lai A. L., Venugopal J. R., Navaneethan B. et al. // Nanomedicine (Lond). - 2015. - 10 (18). - P. 2907-2930.

27. Lee N. Biomimetic strategies for engineering composite tissue / Lee N., Robinson J., Lu H. // Curr. Opin. Biotechnol. - 2016. - 40. - P. 64-74.

28. Lee J. K. The self-assembling process and applications in tissue engineering / Lee J. K., Link J. M., Hu J. C. Y. et al. // Cold Spring Harb. Perspect. Med. - 2017. - 7 (11). - P. a025668.

29. Levy-Mishali M. Effect of scaffold stiffness on myoblast differentiation / Levy-Mishali M., Zoldan J., Levenberd S. // Tissue Engineering Part A. - 2009. - 15. - P. 935944.

30. L’Heureux N. A completely biological tissue engineered human blood vessel / L'Heureux N., Paquet S., Labbe R. et al. // FASEB J. - 1998. - 12. - P. 47-56.

31. Liu X. Polymeric scaffolds for bone tissue engineering / Liu X., Ma P. X. // Annals of Bioneed. Eng. - 2004. - 32. - P. 477-486.

32. Lovati A. B. Decellularized and engineered tendons as biological substitutes: a critical review / Lovati A. B., Botttgisio M., Moretti M. // Stem Cell Intern. - 2016. - 2016. - P. 7276150.

33. Ma D. Engineering scaffold-free bone tissue using bone marrow stromal cell sheets / Ma D., Ren L., Lin Y. et al. // J. Orthop. Res. - 2010. - 28. - P. 697-702.

34. Matthyssen S. Corneal regeneration: a review of stromal replament / Matthyssen S., van den Bogerd B., Dhubhghaills H. et al. // Acta Biomaterials. - 2018. 69. - P. 31-41.

35. Mironov V., Kasyanov V. Emergence of clinical vascular tissue engineering / Mironov V., Kasyanov V. // Lancet. - 2009. - 373. - P. 1402-1404.

36. Mironov V. Organ printing: tissue spheroids as building blocks / Mironov V., Visconti R.P., Kasyanov V. et al. // Biomaterials. - 2009. - 30. - P. 2164-2174.

37. Nishida K. Corneal reconstruction with tissueengineered cell sheet composed of autologous oral mucosal epithelium / Nishida K., Yamato M., Hayashida Y. et al. // N. Engl. J. Med. - 2004. - 351. - P. 1187-1196.
38. Norotte C. Scaffold-free vascular tissue engineering using bioprinting / Norotte C., Marga F. S., Niklason L. E. et al. // Biomaterial. - 2009. - 30. - P. 5910-5917.

39. Ofek G. Matrix development in sell-assembly of articular cartilage / Ofek G., Revell C. M., Hu J. C. et al. // PLoS One. - 2008. - 3. - P. e2795.

40. Paez-mayorga J. Bioreactors for cardiac tissue engineering / Paez-mayorga J., Hemander-Varguas C., Ruir-Esparra G. U. et al. // Adv. Healthc. Mater. - 2019. - 8 (7). - P. e1701504.

41. Paxton J. Z. Engineeering an in vitro model of a functional ligament from bone / Paxton J. Z., Grover L. M., Baar K. // Tissue Eng. Part A. - 2010. - 16. - P. 3515-3525.

42. Peck $M$. The evolution of vascular tissue engineering and current state of the art / Peck M., Gebhart D., Dusserre N. et al. // Cells Tissues Organs. - 2012. - 195. - P. 144-158.

43. Perez-Pomares J. M., Foty R. A. Tissue fusion and cell sorting in embryonic development and disease: biomedical application / Perez-Pomares J. M., Foty R. A. // Bioessays. - 2006. - 28. - P. 809-821.

44. Pillai D. S. Tissue engineering in Achilles tendon reconstruction / Pillai D. S., Dhinsa B. S., Khan W. S. // Curr Stem Cell Res. Ther. - 2017. - 12 (6). - P. 506-512.

45. Pirraco R. P. Development of osteogenetic cell sheets for bone tissue engineering applications / Pirraco R. P., Obokata H., Iwata T. et al. // Tissue Eng. Part A. - 2011. - 17. - P. 507-515.

46. Riccalton-Banks L. Long-term culture of functional liver tissue: three dimensional coculture of primary hepatocytes and stellat cells / Riccalton-Banks L., Liew C., Bhandari R. et al. // Tissue Eng. - 2003. - 9. P. 401-410.

47. Rien C. From tendon insury to collagen-based tendon regeneration / Rien C., Picant L., Mosser G. et al. // Curr. Pharm. Des. - 2017. - 23 (24). - P. 3483-3506.

48. Rosso F. From cell-ECM interaction to tissue engineering / Rosso F. // J. Cell Physiol. - 2004. - 199. - P. 174-180.

49. Sancher-Adams J. Dermis isolated adult stem cells of cartilage tissue engineering / Sancher-Adams J., Athanasion K. A. // Biomaterials. - 2012. - 3. P. 109-119.

50. Sied-Picard F. N. Three- dimentional engineered bone from bone marrow stromal cells and their autogenous extracellular matrix / Sied-Picard F. N., Larkin L. M., Shaw C. M. et al. // Tissue Ing. Part A. - 2009. - 15. P. 187-195.

51. Simon-Yarza T. Cardiovascular bioengineering: current state of the art / Simon-Yarza T., Bataille I., Letourneur D. // J. Cardiovasc. Transl. Res. - 2017. - 10 (2). P. 180-193.

52. Smietana M. J. The effect of implantation on scaffoldess three - dimentional engineered bone constructs / Smietana M. J., Syed-Picard F. N., Ma J. et al. // In Vitro Cell Dev. Biol. Anim. - 2009. - 45. - P. 512-522.

53. Steinberg M. S. Does differential adhesion govern self-assembly processes in histogenesis? Equilibrium 
configurations and the emergence of a hierarchy among populations of embryonic cells / Steinberg M. S. //J. Exp. Zool. - 1970. - 173. - P. 395-433.

54. Strohman R. C. Myogenesis and histogenesis of skeletal muscle on flexible membranes in vitro / Strohman R. C., Bayne E., Spector D. et al. // In Vitro Cell. Devel. Biol. - 1990. - 26. - P. 201-208.

55. Weinberger F. Engineering cardiac muscle tissue: a maturating field of research / Weinberger F., Mannhardt I., Eschnhagen T. // Circ. Res. - 2017. - 120 (9). P. 1487-1500.

56. Yoon D. M. Choudracyte signaling and artificial matrices for articular cartilage engineering / Yoon D. M., Fisher J. P. // Adv. Exp. Med. Biol. - 2006. - 585. - P. 67-86.

57. Youssef J. Quantification of the forces during selfassembly of three-dimensional microtissues / Youssef J., Wurse A. K., Freund L. B. et al. // Proc. Natl. Acad. Sci. VSA. - 2011. - 108. - P. 6993-6998.

58. Yan Z. Boosting tendon repair: interplay of cells, growth factors, and scaffold-free and gel-based carriers / Yan Z., Yin H., Nerlich M. et al. // J. Exp. Orthop. - 2018. -5 (1). - P. 1.

59. Zhang H. Physical micro - environmed - based inducible scaffold for stem cell differentiation and tendon regeneration / Zhang H., Liu M. F., Liu R. C. et al. // Tissue Eng. Part B. Rev. - 2018. - 24 (6). - P. 443-453.

60. Zhao X. Active scaffolds for on-demand drug and cell delivery / Zhao X., Kim J., Cezar C. A. et al. // Proc. Nat. Acad. Sci. USA. - 2011. - 108. - P. 67-72.

61. Orabi H. Scaffoldless tissue engineering of stem cell derived cavernous tissue for treatment of erectile function / Orabi H., Lin G., Ferretti L., Lin C. S., Lue T. F. // J. Sex Med. - 2012. - 9 (6). - P. 1522-34.

62. Whitesides G. M. Self-assembly at all scales / Whitesides G. M., Grzybowski B. // Science. - 2002. - 295. P. 2418-21.

63. Halley J. D. Consistent Concepts of Self-organization and Self-assembly / Halley J. D., Winkler D. A. // Complexity. - 2008. - 14. - P. 10-17.

\section{References.}

1. Timchenko, A. S., Zalessky, V. N.(2018). Mezenkhimalnyye i opukholevyye stvolovyye kletki: mekhanizmy immunovospalitelnoy modulyatsii stvolovykh kletok pri personalizovannoy meditsine: Monografiya [Mesenchymal and tumor stem cells: mechanisms of immuno-inflammatory stem cell modulation in personalized medicine (Monograph)]. Kiev: Medinform. [In Russian].

2. Athanasion K.A., Eswaramoorthy R., Hadidi P. et al. (2013). Seff-organization and self-assembly process in tissue engineering. Annu. Rev. Biomed. Eng., 15, 115-136.

3. Baltich J., Hatch-Vallier L., Adams A.M. et al. (2010). Development of scaffoldless three-dimensional engineered nerve using a nerve fibroblast co-culture. In Vitro Cell Dev. Biol. Anum., 46, 438-444.
4. Brown W. E., Huang B. J., Keown T., Hu J. C., Athanasion K. A. (2018). Overcoming Challenges in engineering large, scaffold-free neocartilage with functional properties. Tissue Eng. Part A., 24 (21-22), 1652-1662.

5. Bollini, S., Silini, A. R., Banerjee, A. et al. (2018). Cardiac restoration stemming from the placenta tree: Insights from fetal and perinatal cell biology. Front Physiol., 9, 385.

6. Calve, S., Lytle, I. F., Grosh, K. et al. (2010). Implantation increases tensile strength and collagen content of selfassembled tendon constructs. J.Appl. Physiol., 108, 875-881.

7. Dean, D. M., Morgan, J. R. (2008). Cytoskeletalmediated tension modulates the directed self-assembly of microtissues. Tissue Eng. Part A., 14, 1989-1997.

8. Discher, D. E., Janmey, P., Wang, Y. L. (2005). Tissue cells feel and respond to the stiffness of their substrate. Science, 310, 1139-1143.

9. Donnelly, K., Khodabukus, A., Philp, A. et al. (2010). A novel bioreactor for stimulating skeletal muscle in vitro. Tissue Eng. Part. C. Methods, 16, 711-718.

10. Elder, S. H., Sanders, S. W., Mc Culley, W. R. et al. (2006). Chondrocyte response to cyclic hydrostatic pressare in alginate versus pellet culture. J. Orthop. Res., 24, 740-747.

11. Eiraku, M., Takata, N., Ishibashi, H. et al. (2011). Self-organizing optic-cup morphogenesis in threedimensional culture. Nature, 472, 51-56.

12. Foty, R. A., Steinberg, M. S. (2005). The differential adhesion hypothesis: a direct evaluation. Dev. Biol., 278, 255-263.

13. Furukawa, K. S., Suenaga, H., Toita, K. et al. (2003). Rapid and large-scale formation of chondrocyte aggregates by rotational culture. Cell Transplant., 12, 475-479.

14. Ganvin, R., Ahsan, T., Larouche, D. et al. (2010). A novel single-step self-assembly approach for the fabrication of tissue-engineering vascular constructs. Tissue Eng. Part A, 16, 1737-1747.

15. Ghezzi, C. E., Rnjak-Kovacina, J., Kaplan, D. L. (2015). Corneal tissue engineering: recent advance and future perspective. Tissue Eng. Part. B. Pev., 21 (3), 278-287.

16. Griffith, M., Jackson, W. B., Lagali, N. et al. (2009). Artificial corneas: a regenerative medicine approach. Eye (Lond), 23, 1985-1989.

17. Griffith, M., Harkin, D. G. (2014). Recent advances in the design of artificial corneas. Curr. Opin. Ophthalmol., 25 (3), 240-247.

18. Halley, J. D., Winkler, D. A. (2008). Consistent concepts of self-organization and sell-assembly. Complexity, 14, 10-17.

19. Haraguchi, Y., Shimizu, T., Sasagawa, T. et al. (2012). Fabrications of functional three-dimensional tissues by stocking cell sheets in vitro. Nat. Protoc., 7, 850-858.

20. Harris, A. K. (1976). Is cell sorting caused by differences in the work of intercellular adhesion? A critical of the Steinberg hypothesis. J. Theor. Biol., 61, 267-285. 
21. Huang, Y. C., Dennis, R. G., Larkin, L. et al. (2005). Rapid formation of functional muscle in vitro using fibril gels. J. Appl. Physiol., 98, 706-713.

22. Huang, Y. C., Dennis, R. G., Baar, K. (2006). Cultured slow versus skeletal muscle cells differ in physiology and responsiveness to stimulation. Am. J. Physiol. Cell Physiol., 291:11, 17.

23. Jakab, K., Narotte, C., Marga, F. et al. (2010). Tissue engineering by self-assembly and bio-printing of living cells. Biofabrication, 2, 02-2001.

24. Kinoshita, N., Sasai, N., Misaki, K. et al. (2008). Apical accumulation of Rho in the neural plate in important for neural plate cell shape change and neural tube formulation. Mol. Biol. Cell, 19, 2289-2299.

25. Komae, H., Ono, M., Shimiru, T. (2008). Sell sheetbased vasenlarized myocardial tissue fabrication. Eur. Surg. Res., 59 (3-4), 276-285.

26. Lai, A. L., Venugopal, J. R., Navaneethan, B. et al. (2015). Biomimetic approaches for cell implantation to the restoration of infarcted myocardium. Nanomedicine (Lond), 10 (18), 2907-2930.

27. Lee, N., Robinson, J., Lu, H. (2016). Biomimetic strategies for engineering composite tissue. Curr. Opin. Biotechnol., 40, 64-74.

28. Lee, J. K., Link, J. M., Hu, J. C. Y. et al. (2017). The self-assembling process and applications in tissue engineering. Cold Spring Harb. Perspect. Med., 7 (11), a025668.

29. Levy-Mishali, M., Zoldan, J., Levenberd, S. (2009). Effect of scaffold stiffness on myoblast differentiation. Tissue Engineering Part A, 15, 935-944.

30. L’Heureux, N., Paquet, S., Labbe, R. et al. (1998). A completely biological tissue-engineered human blood vessel. FASEB J., 12, 47-56.

31. Liu, X., Ma, P. X. (2004). Polymeric scaffolds for bone tissue engineering. Annals of Bioneed. Eng., 32, 477-486.

32. Lovati, A. B., Botttgisio, M., Moretti, M. (2016). Decellularized and engineered tendons as biological substitutes: a critical review. Stem Cell Intern., 7276150.

33. Ma, D., Ren, L., Lin, Y. et al. (2010). Engineering scaffold-free bone tissue using bone marrow stromal cell sheets. J. Orthop. Res., 28, 697-702.

34. Matthyssen, S., van den Bogerd, B., Dhubhghaills, H. et al. (2018). Corneal regeneration: a review of stromal replament. Acta Biomaterials, 69, 31-41.

35. Mironov, V., Kasyanov, V. (2009). Emergence of clinical vascular tissue engineering. Lancet, 373, 1402-1404.

36. Mironov, V., Visconti, R. P., Kasyanov, V. et al. (2009). Organ printing: tissue spheroids as building blocks. Biomaterials, 30, 2164-2174.

37. Nishida, K., Yamato, M., Hayashida, Y. et al. (2004). Corneal reconstruction with tissue-engineered cell sheet composed of autologous oral mucosal epithelium. N. Engl. J. Med., 351, 1187-1196.
38. Norotte, C., Marga, F. S., Niklason, L. E. et al. (2009). Scaffold-free vascular tissue engineering using bioprinting. Biomaterial, 30, 5910-5917.

39. Ofek, G., Revell, C. M., Hu, J. C. et al. (2008). Matrix development in sell-assembly of articular cartilage. PLoS One, 3, e2795.

40. Paez-mayorga, J., Hemander-Varguas, C., Ruir-Esparra, G. U. et al. (2019). Bioreactors for cardiac tissue engineering. Adv. Healthc. Mater., 8 (7), e1701504.

41. Paxton, J. Z., Grover, L. M., Baar, K. (2010). Engineeering an in vitro model of a functional ligament from bone. Tissue Eng. Part A, 16, 3515-3525.

42. Peck, M., Gebhart, D., Dusserre, N. et al. (2012). The evolution of vascular tissue engineering and current state of the art. Cells Tissues Organs, 195, 144-158.

43. Perez-Pomares, J. M., Foty, R. A. (2006). Tissue fusion and cell sorting in embryonic development and disease: biomedical application. BioEssays, 28, 809-821.

44. Pillai, D. S., Dhinsa, B. S., Khan, W. S. (2017). Tissue engineering in Achilles tendon reconstruction. Curr Stem Cell Res. Ther., 12 (6), 506-512.

45. Pirraco, R. P., Obokata, H., Iwata, T. et al. (2011). Development of osteogenetic cell sheets for bone tissue engineering applications. Tissue Eng. Part A, 17, 507-515.

46. Riccalton-Banks, L., Liew, C., Bhandari, R. et al. (2003). Long-term culture of functional liver tissue: three dimensional coculture of primary hepatocytes and stellat cells. Tissue Eng., 9, 401-410.

47. Rien, C., Picant, L., Mosser, G. et al. (2017). From tendon insury to collagen-based tendon regeneration. Curr. Pharm. Des., 23 (24), 3483-3506.

48. Rosso, F. (2004). From cell-ECM interaction to tissue engineering. J. Cell Physiol., 199, 174-180.

49. Sancher-Adams, J., Athanasion, K. A. (2012). Dermis isolated adult stem cells of cartilage tissue engineering. Biomaterials, 3, 109-119.

50. Sied-Picard, F. N., Larkin, L. M., Shaw, C. M. et al. (2009). Three-dimentional engineered bone from bone marrow stromal cells and their autogenous extracellular matrix. Tissue Ing. Part A, 15, 187-195.

51. Simon-Yarza, T., Bataille, I., Letourneur, D. (2017). Cardiovascular bioengineering: current state of the art. J. Cardiovasc. Transl. Res., 10 (2), 180-193.

52. Smietana, M. J., Syed-Picard, F. N., Ma, J. et al. (2009). The effect of implantation on scaffoldess threedimentional engineered bone constructs. In Vitro Cell Dev. Biol. Anim., 45, 512-522.

53. Steinberg, M. S. (1970). Does differential adhesion govern self-assembly processes in histogenesis? Equilibrium configurations and the emergence of a hierarchy among populations of embryonic cells. J. Exp. Zool., 173, 395-433.

54. Strohman, R. C., Bayne, E., Spector, D. et al. (1990). Myogenesis and histogenesis of skeletal muscle on flexible membranes in vitro. In Vitro Cell. Devel. Biol., 26, 201-208. 
55. Weinberger, F., Mannhardt, I., Eschnhagen, T. (2017). Engineering cardiac muscle tissue: a maturating field of research. Circ. Res., 120 (9), 1487-1500.

56. Yoon, D. M., Fisher, J. P. (2006). Choudracyte signaling and artificial matrices for articular cartilage engineering. Adv. Exp. Med. Biol., 585, 67-86.

57. Youssef, J., Wurse, A. K., Freund, L. B. et al. (2011). Quantification of the forces during self-assembly of three-dimensional microtissues. Proc. Natl. Acad. Sci. VSA, 108, 6993-6998.

58. Yan, Z., Yin, H., Nerlich, M. et al. (2018). Boosting tendon repair: interplay of cells, growth factors, and scaffold-free and gel-based carriers. J. Exp. Orthop., 5 (1), 1.

59. Zhang, H., Liu, M. F., Liu, R. C. et al. (2018). Physical micro - environmed - based inducible scaffold for stem cell differentiation and tendon regeneration. Tissue Eng. Part B. Rev., 24 (6), 443-453.

60. Zhao, X., Kim, J., Cezar, C. A. et al. (2011). Active scaffolds for on-demand drug and cell delivery. Proc. Nat. Acad. Sci. USA, 108, 67-72.

61. Orabi, H., Lin, G., Ferretti, L., Lin, C. S., Lue, T. F. (2012). Scaffoldless tissue engineering of stem cell derived cavernous tissue for treatment of erectile function. J. Sex Med., 9(6), 1522-34. doi: 10.1111/j.17436109.2012.02727.x.

62. Whitesides, G. M., Grzybowski, B. (2002). Selfassembly at all scales. Science, 295, 2418-21.

63. Halley, J. D., Winkler, D. A. (2008). Consistent Concepts of Self-organization and Self-assembly. Complexity, 14, 10-17. 